\title{
IL-9-producing invariant NKT cells protect against DSS-induced colitis in an IL-4-dependent manner
}

\author{
HS Kim ${ }^{1}$ and DH Chung ${ }^{1}$
}

\begin{abstract}
Although the T-helper type 9 (Th9) subset has recently been revisited, interleukin (IL)-9-producing invariant natural killer T (iNKT) cells remain poorly characterized. Moreover, whether IL-9-producing iNKT cells regulate colitis is unknown. Here, we investigated functions of IL-9-producing iNKT cells in dextran sulfate sodium (DSS)-induced colitis. Wildtype (WT) mice attenuated colitis compared to $\mathrm{J} \alpha 18^{-/-}$mice, which were restored by the adoptive transfer of WT, but not IL-4-deficient iNKT cells. IL-4-deficient iNKT cells failed to produce IL-9, which was reversed by recombinant IL-4. Furthermore, iNKT cells, pre-incubated with anti-CD3 + CD28 monoclonal antibodies and IL-4 + tumor growth factor (TGF)- $\beta$ (IL-9+ iNKT), suppressed colitis in J $\alpha 18^{-/-}$mice, whereas pre-incubated IL-4-deficient iNKT cells did not. IL-9 blockade reversed IL-9+ iNKT cell-mediated colitis by increasing colonic IL-17A and interferon (IFN)- $\gamma$ transcripts, but decreasing IL-9, IL-10, TGF- $\beta$, PU.1, IFN regulatory factor 4, and signal transducer and activator of transcription 5 in $\mathrm{J} \alpha 18^{-/-}$mice. In conclusion, IL-9-producing iNKT cells protect against DSS-induced colitis through IFN- $\gamma$ and IL-17A suppression, but IL-10 and TGF- $\beta$ enhancement, depending on the IL-4 production by iNKT cells.
\end{abstract}

\section{INTRODUCTION}

Diverse CD4 ${ }^{+} \mathrm{T}$-cell subsets regulate immune responses to transplantation, infection, tumor surveillance, and autoimmune diseases. ${ }^{1}$ In recent years, our knowledge of $\mathrm{CD} 4^{+}$ T-cell differentiation has significantly increased, and new subsets continue to be identified and defined. ${ }^{2} \mathrm{CD} 4^{+} \mathrm{T}$-cell subsets have been reorganized as T-helper type 1 (Th) 1 , Th2, regulatory $\mathrm{T}$ (Treg), and Th17 cells. $^{2}$ Recent studies have demonstrated that naïve $\mathrm{CD} 4^{+} \mathrm{T}$ cells differentiate into a distinct subset that produces interleukin (IL)-9 in a specific microenvironment, referred to as Th9 cells. ${ }^{3,4}$ Thus, the concept and function of IL-9-producing CD4 ${ }^{+} \mathrm{T}$-cell subsets have been recently revisited. However, several studies have demonstrated that not only the Th9 subset but also Treg, Th2, and Th17 cells produce IL-9, indicating that various T-cell subsets regulate immune responses through IL-9 production. ${ }^{5}$ Although IL-9 was originally considered a Th2-type cytokine, IL-9 has been implicated in various immune diseases such as allergy, experimental allergic encephalomyelitis, parasite infection, and transplantation. ${ }^{5}$ Nonetheless, the function of IL-9 in inflammatory bowel disease remains unclear.

Natural killer T (NKT) cells are a distinct T-cell subset characterized by the expression of both NK receptors and semi-invariant T-cell receptors (TCRs). ${ }^{6}$ These cells recognize glycolipids presented by CD1d, a major histocompatibility complex (MHC) class I-like protein expressed by antigen-presenting cells. ${ }^{6}$ Upon TCR engagement, invariant (i) NKT cells rapidly secret large amounts of IL-4, interferon (IFN)- $\gamma$, and IL-10 in vivo, which plays a crucial role in the regulation of immune responses by balancing the Th1 vs. Th2 cytokine microenvironment. ${ }^{7,8}$ Furthermore, iNKT cells also produce IL-13, which regulates immune responses in asthma and oxazolone-induced colitis. ${ }^{9,10}$ These findings suggest that iNKT cells regulate diverse immune diseases by producing a variety of cytokines compared with conventional $\mathrm{CD} 4^{+} \mathrm{T}$ cells. Several studies have shown that $\mathrm{DX} 5^{+} \mathrm{CD} 3^{+}$ spleen cells, NK1.1 ${ }^{+} \mathrm{CD} 4^{+} \mathrm{T}$ cells, and NK1.1- $\mathrm{CD} 4^{-}$IL-17producing NKT cells produce IL-9 in vitro, ${ }^{11-13}$ suggesting that iNKT cells produce IL-9 upon stimulation in vitro and in vivo. However, IL-9-producing iNKT cells are poorly characterized as a newly defined cell subset in terms of Th9-related inducible transcriptional factors and the cytokine microenvironment. Furthermore, it has not been explored whether IL-9-producing iNKT cells contribute to development and regulation of inflammatory bowel disease. Therefore, in this study, we explored whether IL-9-producing iNKT cells regulate dextran sulfate sodium (DSS)-induced colitis by characterization of IL-9-producing iNKT cells in vitro and in vivo. In our

\footnotetext{
${ }^{1}$ Department of Pathology and Laboratory of Immune Regulation in Department of Biomedical Sciences, Seoul National University College of Medicine, Seoul, Korea. Correspondence: DH Chung (doohyun@snu.ac.kr) 
experiments, IL-9-producing iNKT cells protect against DSSinduced colitis by suppressing IFN- $\gamma$ and IL-17A production. Moreover, iNKT cells produced IL-9 upon stimulation with TCR, which was enhanced by additional stimulation with IL-4 and tumor growth factor (TGF) $\beta$ in vitro and was dependent on IL-4 produced by iNKT cells.

\section{RESULTS}

\section{iNKT cells protect against DSS-induced colitis}

To explore whether iNKT cells regulate the immune response by producing IL-9 in vivo, we compared wild-type (WT) B6 and J $\alpha 18^{-/-}$mice in the DSS-induced colitis model. The body weights of WT B6 mice decreased from 5 to 7 days and then gradually increased to 10 days during 3 and 3.5\% DSS-induced colitis, whereas those of $\mathrm{J} \alpha 18^{-/-}$mice continuously decreased after 5-7 days (Figure 1a). During 3.5\% DSS-induced colitis, all WT B6 mice were alive up to 10 days, whereas all J $\alpha 18^{-/-}$ mice died within 6-8 days (Figure 1a). Furthermore, inflammation in the colon was more severe in J $\alpha 18^{-/-}$mice than in WT B6 mice (Figure 1b). These findings indicate that iNKT cells play a protective role in DSS-induced colitis.

Serum IL-4, IL-9, IL-10, IL-13, and TGF- $\beta$ levels were higher in WT mice than in $\mathrm{J} 18^{-1-}$ mice, whereas the serum IFN- $\gamma$ and IL-17A levels in WT mice were reduced (Figure 1c). Serum cytokine levels in the two mouse groups were consistent with the transcript levels of these cytokines in the colon (Figure 1d). Signal transducer and activator of transcription (STAT) 5, IFN regulatory factor 4 (IRF4), and IL-22 transcript levels were increased in the colon of WT mice compared with $\mathrm{J} 18^{-/-}$ mice, whereas STAT1 and STAT3 transcript levels were higher in J $\alpha 18^{-/-}$mice than in WT mice (Figure 1d). Furthermore, a significant fraction of IL-9-producing $\alpha$-galactosylceramide $\left(\alpha\right.$-GalCer)/CD1d tetramer ${ }^{+}$iNKT cells were detected in the colon from WT mice during DSS-induced colitis, which was higher than IL-9-producing Lin ${ }^{-}$Thy $1.2^{+}$innate lymphoid cells, suggesting that colonic iNKT and innate lymphoid cells produce IL-9 during DSS-induced colitis (Figure 1e). However, conventional T cells minimally produced intracellular IL-9 in the colon during DSS-induced colitis. The IL-9 levels in the culture fraction of colonic immune cells in WT mice with colitis were higher than those in J $\alpha 18^{-/-}$mice with colitis (Figure 1f). Collectively, these findings suggest that iNKT cells produce IL-9 in the colon, which might contribute to attenuating DSS-induced colitis.

\section{iNKT cells produce IL-9 under TCR stimulation alone or IL-9-polarizing conditions}

To address whether iNKT cells protect against DSS-induced colitis by producing IL-9, we explored whether iNKT cells produce IL-9 in vitro. Sorted CD4 ${ }^{+} \mathrm{T}$ cells from liver mononuclear cells (LMNCs) of WT B6 or NKT cell-deficient mice were cultured under IL-9-polarizing conditions and intracellular staining for IL-9 was performed. A significant percentage of $\mathrm{CD} 4^{+} \mathrm{T}$ cells from WT B6 mice showed intracellular IL-9 compared with negative control groups. However, a lower percentage of CD4 ${ }^{+}$ $\mathrm{T}$ cells from $\mathrm{J} \alpha 18^{-/-}$and $\mathrm{CD} 1 \mathrm{~d}^{-/-}$mice expressed intracellular IL-9 compared with those of WT B6 mice (Figure 2a). Consistent with these findings, the IL-9 levels in the culture supernatant fraction of $\mathrm{CD} 4^{+} \mathrm{T}$ cells from WT B6 mice were higher than those of $\mathrm{J} \alpha 18^{-/-}$and $\mathrm{CD} 1 \mathrm{~d}^{-/-}$mice (Figure $2 \mathbf{b}$ ). Furthermore, IL-9 was detected in the cytoplasm of gated $\alpha$-GalCer/CD1d tetramer ${ }^{+}$iNKT cells from WT B6 mice (Figure 2c). These findings suggest that iNKT cells produce IL-9 in IL-9-polarizing conditions. Next, to explore whether TCR-activated iNKT cells alone produce IL-9 in vitro, sorted iNKT cells were incubated with anti-CD3 and CD28 monoclonal antibodies (mAbs). The IL-9 levels gradually increased with increased incubation time upon CD3 and CD28 stimulation, suggesting that iNKT cells produce IL- 9 by TCR stimulation alone. Furthermore, serum IL-9 levels in WT B6 mice gradually increased from 20 to $72 \mathrm{~h}$, whereas IL- 4 and IFN- $\gamma$ levels peaked after 4 and $50 \mathrm{~h}$ following $\alpha$-GalCer injection (Figure 2d). In contrast, J $\alpha 18^{-1-}$ mice produced minimal amounts of IL-9, IL-4, and IFN- $\gamma$ upon $\alpha$-GalCer injection. These findings indicate that iNKT cells produce IL-9 upon TCR stimulation alone in vitro and in vivo. Next, we compared the capability of IL-9 production and IL-9-related transcription factor expression by iNKT cells upon stimulation with TCR alone and under IL-9polarizing conditions. Upon stimulation with anti-CD3 and CD28 mAbs alone, iNKT cells produced a significant amount of IL-9, whereas iNKT cells produced larger amounts of IL-4 and IFN- $\gamma$. In contrast, iNKT cells secreted higher levels of IL-9, but minimal IL-4 and IFN- $\gamma$ in IL-9-polarizing conditions compared with anti-CD3 $+\mathrm{CD} 28 \mathrm{mAb}$ stimulation alone (Figure 2e). These results indicate that IL-9-polarizing conditions enhance IL- 9 production, but suppress IL- 4 and IFN- $\gamma$ production by iNKT cells. With respect to transcription factors, IL-9-polarizing conditions enhanced PU.1 and IRF4 expression

Figure 1 Invariant natural killer T (iNKT) cell-deficient mice aggravate dextran sodium sulfate (DSS)-induced colitis. (a) Body weights (percentage of body weights relative to initial body weights) of wild-type (WT) and J $\alpha 18^{-1-}$ mice were measured after 3 and $3.5 \%$ DSS treatment and survival percentages of WT and $\mathrm{J} \alpha 18^{-/-}$mice were estimated 10 days after 3.5\% DSS treatment. (b) Histological examination of the colons of WT and $\mathrm{J} \alpha 18^{-/-}$mice with or without colitis (hematoxylin and eosin (H\&E) staining, original magnification $\left.\times 100\right) 10$ days after $3 \%$ DSS treatment. (c) Serum interleukin (IL)-4, IL-9, IL-10, IL-13, IL-17, interferon (IFN)- $\gamma$, and tumor growth factor (TGF)- $\beta$ levels were measured in WT and Ja18 ${ }^{-/-}$mice $0,3,5$, 7 , and 10 days after $3 \%$ DSS treatment using enzyme-linked immunosorbent assay (ELISA). (d) Colonic IL-4, IL-9, IL-10, IL-17, IFN- $\gamma$, TGF- $\beta$, signal transducer and activator of transcription (STAT)1, STAT3, STAT5, IFN regulatory factor 4 (IRF4), IL-22, and PU.1 transcript levels were determined using real-time polymerase chain reaction (PCR) in WT and Ja18 $18^{-/-}$mice 10 days after DSS treatment. (e) Intracellular IL-9 expression was detected in $\alpha$-galactosylceramide ( $\alpha$-GalCer)/CD1d tetramer ${ }^{+}$iNKT cells, Lin-Thy1.2 ${ }^{+}$innate lymphoid cells (ILC), or $\alpha$-GalCer/CD1d tetramer- $\alpha \beta$ TCR ${ }^{+}$ conventional T cells of the colon from WT mice 10 days after $3 \%$ DSS treatment. (f) IL-9 production was measured in supernatant of cultured colonic immune cells from WT and Ja18 $18^{-/}$mice 10 days after $3 \%$ DSS treatment. Data are representative of three repeated independent experiments ( $n=6$ in $\mathbf{a}, \mathbf{b}, \mathbf{d} ; n=5$ in $\mathbf{c} ; n=3$ in $\mathbf{d}, \mathbf{e}$, and $\left.\mathbf{f} ;{ }^{*} P<0.05,{ }^{* \star} P<0.01,{ }^{* * *} P<0.001\right)$. GAPDH, glyceraldehyde 3-phosphate dehydrogenase. 
in iNKT cells, but suppressed T-bet and GATA-3 expression (Figure 2f). However, anti-CD3 + CD28 mAb stimulation alone minimally enhanced PU.1 and IRF4 expression, but enhanced T-bet and GATA-3 expression in iNKT cells. These findings suggest that IL-9 production by iNKT cells may be functionally associated with PU.1 and IRF4 expression rather than T-bet and GATA-3 in IL-9-polarizing conditions, whereas
iNKT cells produce IL-9 upon TCR stimulation alone in a PU.1- and IRF4-independent manner.

\section{IL-4-producing iNKT cells is crucial in IL-9 production by iNKT cells}

To investigate whether the IL- 4 and IFN- $\gamma$ produced by iNKT cells regulates IL-9 production by iNKT cells, WT B6, IL-4 ${ }^{-/-}$, a
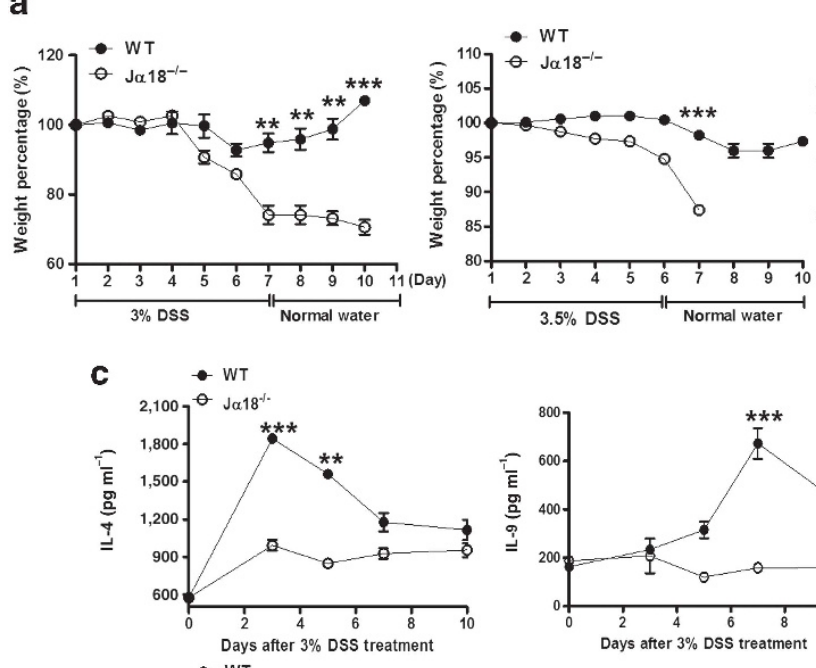

- WT
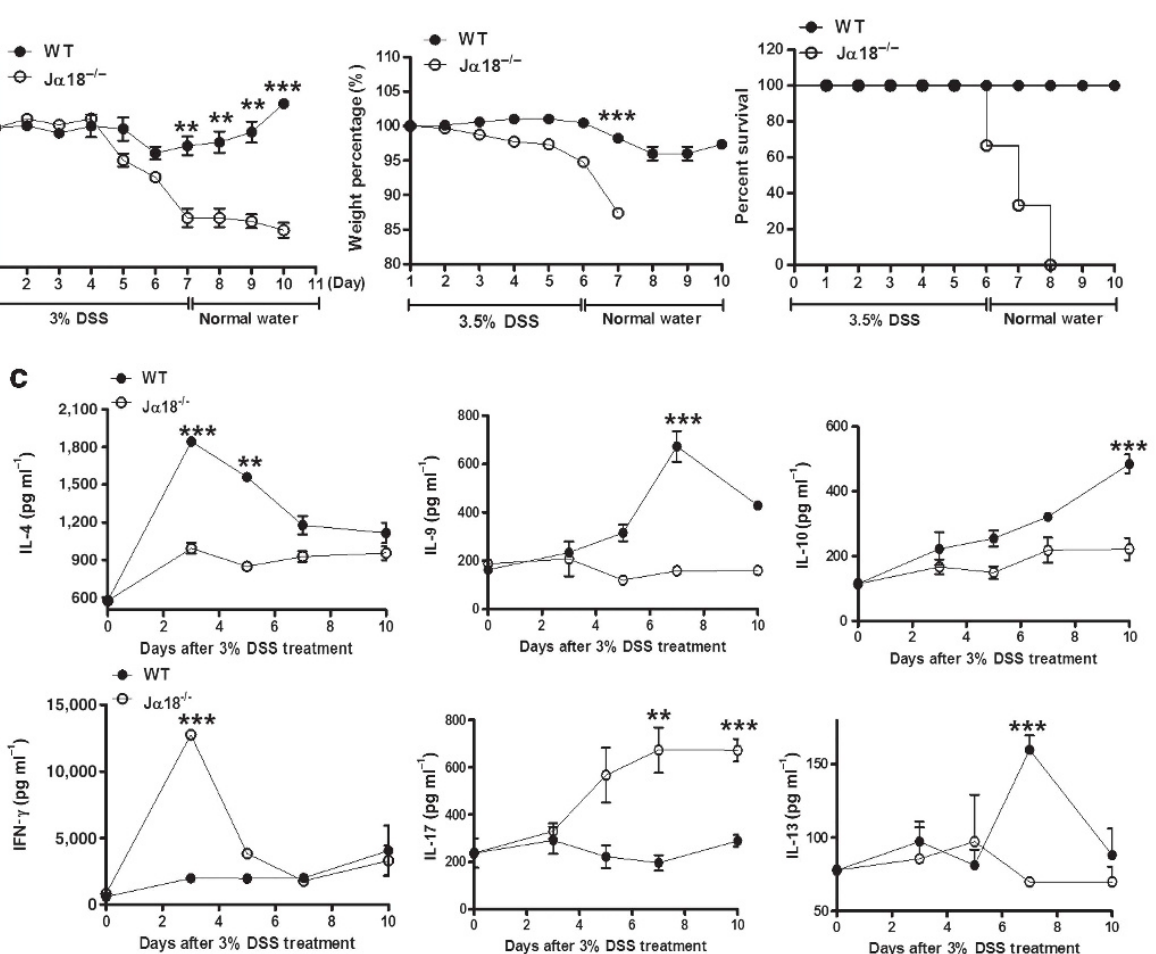

b

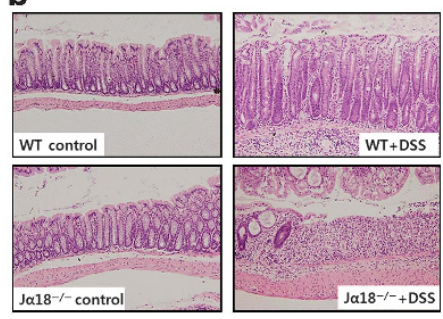

d
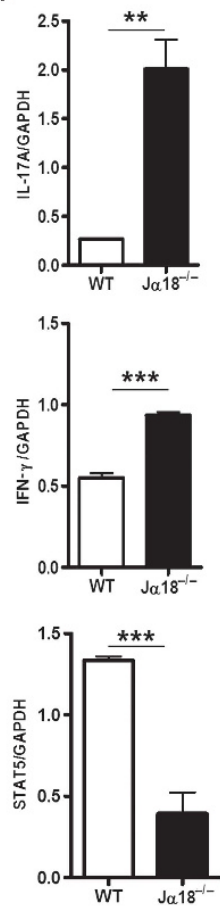
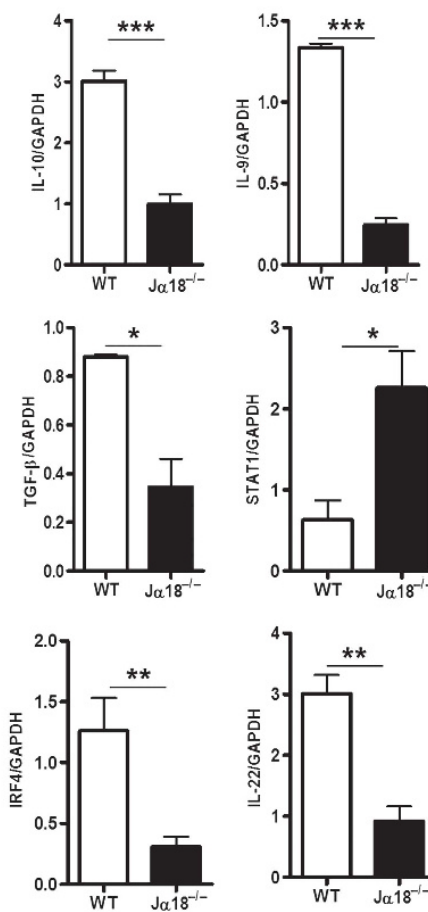
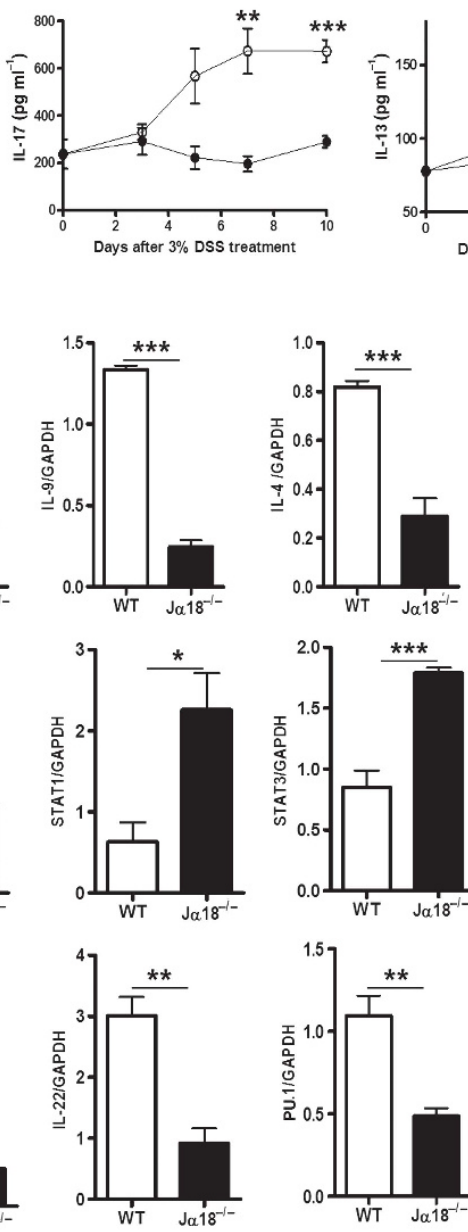
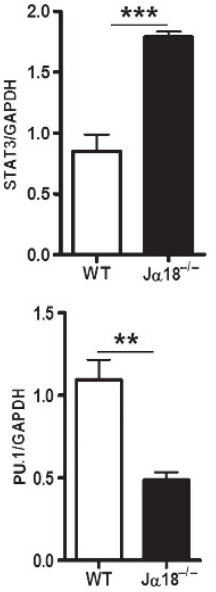

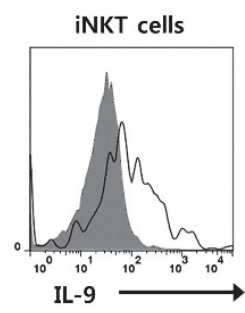

Lin-Thy1.2+ ILC

Non-iNKT cells (T cells)
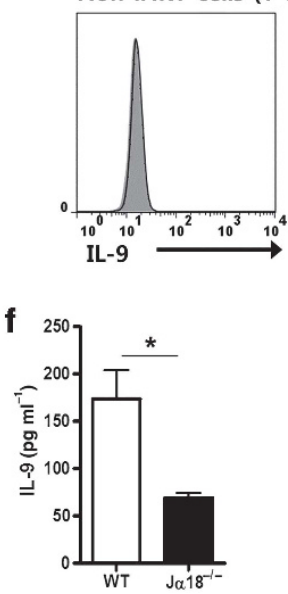


\section{ARTICLES}

and IFN- $\gamma^{-1-}$ mice were injected with $\alpha$-GalCer. $\alpha$-GalCer injection minimally enhanced IL- 4 or IFN- $\gamma$ in IL- $4^{-1-}$ or IFN$\gamma^{-1-}$ mice compared with WT B6 mice. However, $\alpha$-GalCer injection did not alter serum TGF- $\beta$ levels in WT B6, IL-4 $4^{-/-}$, and IFN- $\gamma^{-/-}$mice. It also enhanced serum IL-9 levels in WT and IFN- $\gamma^{-1-}$ mice, but had no effect in IL- $4^{-1-}$ mice (Figure 3a). These findings suggest that the IL-4 production by iNKT cells enhances, but IFN- $\gamma$ suppresses IL-9 production

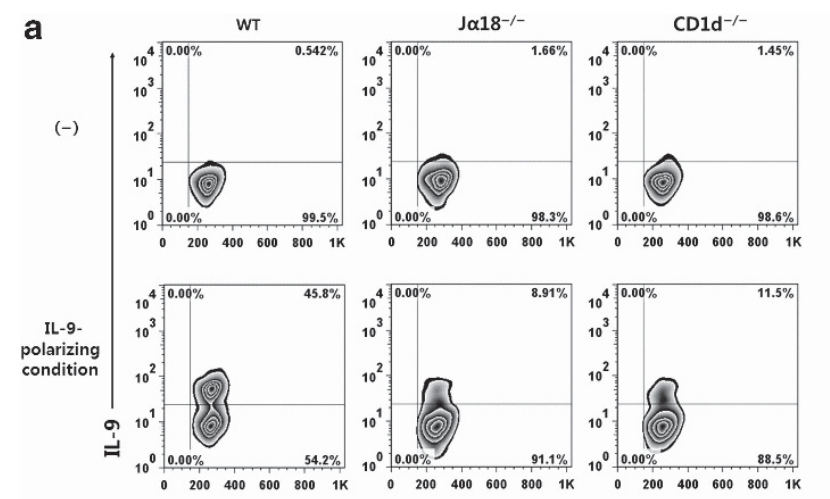

b

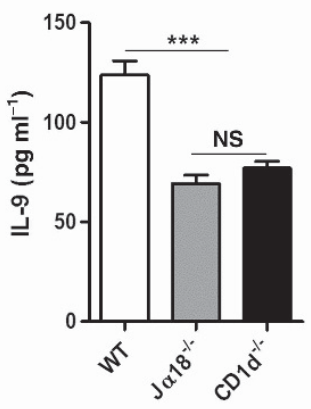

C

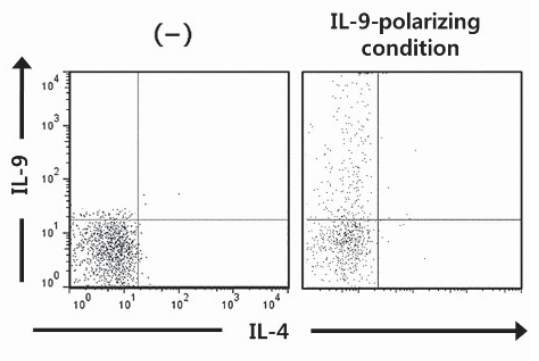

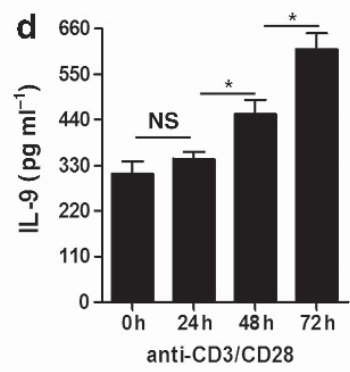
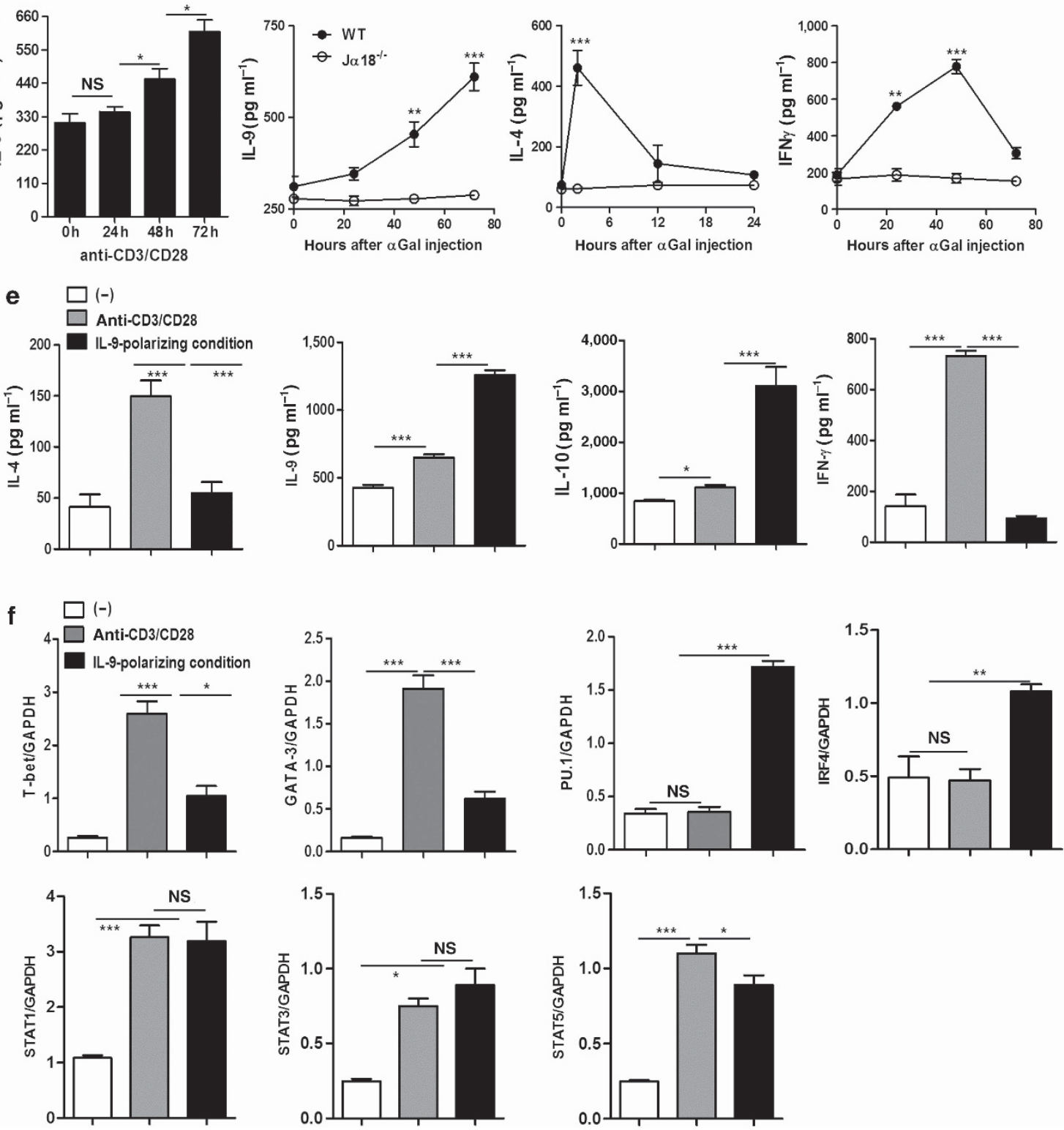
by iNKT cells in vivo, whereas TGF- $\beta$ minimally regulates IL-9 production by iNKT cells upon TCR stimulation.

To confirm this, LMNCs from WT B6, IL-4-1-, or IFN- $\gamma^{-/-}$ mice were incubated with $\alpha$-GalCer (Figure $3 \mathbf{b}$ and $\mathbf{c}$ ). IL-4deficient LMNCs had fewer, and IFN- $\gamma$-deficient LMNCs had more, IL-9-producing iNKT cells than WT LMNCs. The addition of recombinant IL- 4 or IFN- $\gamma$ restored the percentage of IL-9-producing iNKT in LMNCs from IL-4 ${ }^{-/-}$or IFN- $\gamma^{-/-}$ mice, respectively. Moreover, anti-IL-4 receptor (R) mAb in WT iNKT cells and recombinant IFN- $\gamma$ treatment in IFN- $\gamma$-deficient iNKT cells reduced IL-9-producing iNKT cells, whereas antiIFN- $\gamma \mathrm{R}$ mAb in WT iNKT cells and the treatment of IL-4-deficient iNKT cells with recombinant IL-4 increased IL-9 iNKT cell production. In contrast, anti-IL-4R or IFN- $\gamma \mathrm{R}$ mAb did not affect IL- 9 production by IL-4- or IFN- $\gamma$-deficient iNKT cells stimulated with $\alpha$-GalCer, respectively. Consistent with these findings, percentages of IL-9-producing iNKT cells significantly reduced in the absence of IL- 4 during incubation of LMNCs of WT B6 mice under IL-9-polarizing conditions, whereas absence of TGF- $\beta$, IL- 2 , or anti-IFN- $\gamma$ mAb less affected IL-9-producing iNKT cells than that of IL-4 (Figure 3d). These findings suggest that IL-4 might be more crucial for induction of IL-9-producing iNKT cells than TGF- $\beta$, and that autocrine and/or paracrine IL- 4 production by iNKT cells plays a crucial role in the induction of IL-9-producing iNKT cells in vitro and in vivo.

\section{IL-9-producing iNKT cells attenuate DSS-induced colitis by suppressing IFN- $\gamma$ and IL-17A, but enhancing IL-10 and TGF- $\beta$ production}

To address this suggestion, WT or IL-4-deficient iNKT cells were adoptively transferred into $\mathrm{J} \alpha 18^{-/-}$mice during DSS-induced colitis. On the basis of a failure of IL-4-deficient iNKT cells in IL-9 production upon TCR stimulation in vitro and in vivo (Figure 3a and $\mathbf{b}$ ), we postulated that adoptively transferred WT cells, but not IL-4-deficient iNKT cells, produce IL-9 during DSS-induced colitis. The adoptive transfer of WT iNKT cells into J $\alpha 18^{-/-}$mice attenuated colitis in terms of body weight and colon length, whereas those of IL-4-deficient iNKT cells remained unchanged (Figure $4 \mathbf{a}$ and $\mathbf{b}$ ). Moreover, WT iNKT cells increased the levels of IL-9, IL-4, IL-10, and TGF- $\beta$ transcript levels in the colon in $J \alpha 18^{-/-}$mice, whereas these cells decreased IFN- $\gamma$ and IL-17A transcript levels during
DSS-induced colitis. In contrast to WT iNKT cells, IL-4-deficient iNKT cells did not restore the transcript levels of these cytokines and the transcriptional factors in the colon during DSS-induced colitis (Figure 4c). Taken together, iNKT cells might produce IL-9 in an IL-4-dependent manner during DSSinduced colitis. However, it is unclear whether IL-9-producing iNKT cells protect against DSS-induced colitis and whether IL-4-dependent IL-10 and TGF- $\beta$ production in the colon might be related to IL-9-producing iNKT cells.

To address this, $J \alpha 18^{-/-}$mice were adoptively transferred with pre-cultured WT (IL- ${ }^{+}$iNKT) or IL-4-deficient iNKT cells (IL-9- ${ }^{-}$iNKT) under IL-9-polarizing conditions during DSS-induced colitis. IL- $9^{+}$iNKT cells attenuated DSS-induced colitis in J $\alpha 18^{-/-}$mice in terms of body weight, intestinal length, and histological alterations, whereas IL- $9^{-}$iNKT cells failed to alter colitis (Figure 5a-d). During DSS-induced colitis, the IL-9- iNKT cells did not affect the cytokine levels or transcription factors in the colon of J $\alpha 18^{-/-}$mice. In contrast, IL-9 ${ }^{+}$ iNKT cells decreased colonic IL-17A, IFN- $\gamma$, STAT1, and STAT3 transcript levels, but increased IL-9, IL-10, TGF- $\beta$, PU.1, IRF4, and STAT5 in J $\alpha 18^{-/-}$mice (Figure 5e). These findings suggest that IL- $9^{+}$iNKT cells enhance IL-9 production, but inhibit Th1 and Th17 responses in the colon.

To confirm whether iNKT cells regulate DSS-induced colitis by producing IL-9, neutralizing anti-IL-9 $\mathrm{mAb}$ or control immunoglobulin $\mathrm{G}(\mathrm{IgG})$ were intravenously injected into WT, $\mathrm{J} \alpha 18^{-/-}$, or $\mathrm{J} \alpha 18^{-/-}$mice administered IL- $9^{+}$iNKT cells. AntiIL-9 $\mathrm{mAb}$ enhanced transcriptional levels of IFN $-\gamma$ and IL-17A, but reduced those of IL- 10 and TGF- $\beta$ in both WT and J $\alpha 18^{-/-}$ mice (Figure 6a). However, anti-IL-9 mAb aggravated DSSinduced colitis in WT mice, whereas it did not affect colitis in J $\alpha 18^{-/-}$mice, suggesting that IL-9 might protect DSS-induced colitis in an iNKT-dependent manner (Figure 6b). Anti-IL-9 $\mathrm{mAb}$ restored DSS-induced colitis in J $\alpha 18^{-/-}$mice adoptively transferred with IL- $9^{+}$iNKT cells in terms of their body weight and colonic length compared with control IgG (Figure 6c-e). With respect to transcription factors, colonic PU.1, IRF4, and STAT5 transcript levels were reduced upon IL-9 blockade in J $\alpha 18^{-/-}$mice given IL- $9^{+}$iNKT cells compared with control IgG. Furthermore, anti-IL-9 mAb increased both IL-17A and IFN- $\gamma$ production in the colon of $J \alpha 18^{-/-}$mice adoptively transferred with IL- $9^{+}$iNKT cells, whereas IL-10 and TGF- $\beta$ production was decreased (Figure 6f). However, ROR $\gamma$ t expression

Figure 2 Invariant natural killer T (iNKT) cells produce interleukin (IL)-9 by T-cell receptor (TCR) stimulation alone or in IL-9-polarizing conditions. (a and $\mathbf{b}$ ) Intracellular IL-9 expression in sorted CD4 $4^{+}$T cells of wild-type (WT) B6, $\mathrm{J}_{1} 18^{-/-}$, and CD1 $\mathrm{d}^{-/-}$mice, and levels of IL-9 were estimated after incubation in IL-9-polarizing conditions $\left(20 \mathrm{ng} \mathrm{ml}^{-1}\right.$ of recombinant IL-4, $10 \mathrm{ng} \mathrm{ml}^{-1}$ of tumor growth factor (TGF)- $\beta, 10 \mathrm{ng} \mathrm{ml}^{-1} \mathrm{of} \mathrm{IL-2}^{-2}$ and $10 \mu \mathrm{g} \mathrm{ml}-1$ of anti-interferon (IFN)- $\gamma$ monoclonal antibody (mAb)) by flow cytometric analysis and enzyme-linked immunosorbent assay (ELISA), respectively. (c) Cytoplasmic IL-9 was measured in gated $\alpha$-galactosylceramide $\left(\alpha\right.$-GalCer)/CD1d tetramer ${ }^{+}$iNKT cells in WT B6 mouse liver after incubation in IL-9-polarizing conditions. (d) IL-9 produced by sorted $\alpha$-GalCer/CD1d tetramer ${ }^{+}$iNKT cells was estimated following incubation with coated anti-CD3 $\left(5 \mu \mathrm{g} \mathrm{ml}^{-1}\right)+$ anti-CD28 $\left(5 \mu \mathrm{g} \mathrm{ml}^{-1}\right) \mathrm{mAb}$ (left one panel). In WT and J $\alpha 18^{-1-}$ mice injected with $\alpha$-GalCer, serum IL-9, IL-4, and IFN- $\gamma$ was measured by ELISA (right three panels). (e and f) Sorted $\alpha$-GalCer/CD1d tetramer ${ }^{+}$iNKT cells were cultured with IL-9-polarizing conditions and/or anti-CD3/CD28 mAb. (e) IL-4, IL-9, IL-10, and IFN- $\gamma$ production was measured in culture supernatants by ELISA. (f) T-bet, GATA-3, PU.1, IFN regulatory factor 4 (IRF4), signal transducer and activator of transcription (STAT)-1, STAT-3, and STAT-5 transcripts were estimated using real-time polymerase chain reaction (PCR). Data are representative of three repeated independent experiments ( $n=5$ in $\mathbf{a}, \mathbf{d} ; n=3$ in $\left.\mathbf{b}, \mathbf{c}, \mathbf{e}, \mathbf{f} ;{ }^{\star} P<0.05,{ }^{\star \star} P<0.01,{ }^{\star \star \star} P<0.001\right)$. NS, nonsignificant. 

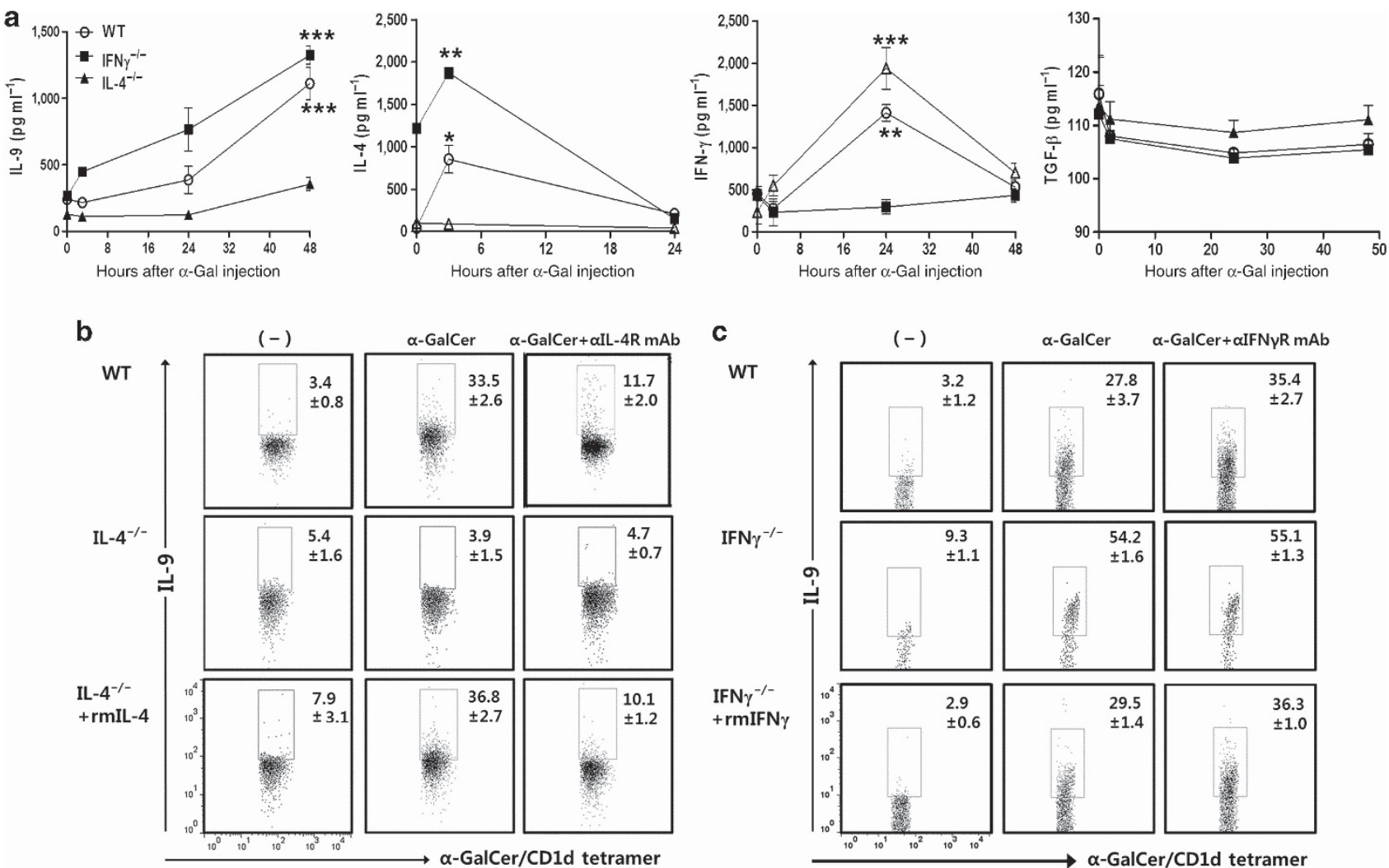

d
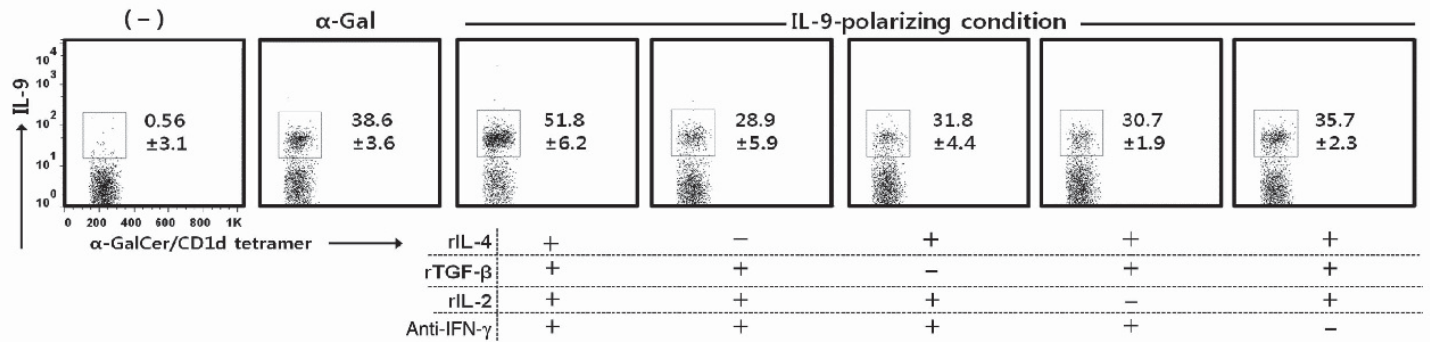

Figure 3 Interleukin (IL)-4-producing invariant natural killer T (iNKT) cells enhance, but interferon (IFN)- $\gamma$-producing iNKT cells suppress, IL-9 production by iNKT cells. (a) Serum IL-9, IL-4, IFN- $\gamma$, and tumor growth factor (TGF)- $\beta$ were measured in wild-type (WT), IL-4 $4^{-/-}$, and IFN- $\gamma^{-/-}$mice injected with $\alpha$-galactosylceramide ( $\alpha$-GalCer) at the designated time points. (b) Liver mononuclear cells (LMNCs) from WT or IL-4 $4^{-/-}$mice were cultured with recombinant IL-4 $\left(20 \mathrm{ng} \mathrm{ml}^{-1}\right)$ or anti-IL-4 receptor monoclonal antibody (mAb) $\left(20 \mathrm{ng} \mathrm{ml}^{-1}\right)$ in the presence or absence of $\alpha$-GalCer for $72 \mathrm{~h}$. (c) WT or IFN- $\gamma$-deficient LMNCs were cultured with recombinant IFN- $\gamma\left(10 \mathrm{ng} \mathrm{ml}^{-1}\right)$ or anti-IFN- $\gamma$ receptor $\mathrm{mAb}\left(1 \mu \mathrm{g} \mathrm{ml}{ }^{-1}\right)$ in the presence or absence of $\alpha$-GalCer for $72 \mathrm{~h}$. (d) LMNCs from WT mice were cultured under IL-9-polarizing conditions in the absence of individual component. (b-d) Intracellular IL-9 expression in $\alpha$-GalCer/CD1d tetramer ${ }^{+}$iNKT cells was estimated and numbers in diagrams represent the percentages of IL-9-producing iNKT cells among total iNKT cells. Data are representative of three repeated independent experiments $(n=5$ in $\mathbf{a} ; n=3$ in $\mathbf{b}, \mathbf{c}, \mathbf{d}$; $\left.{ }^{\star} P<0.05,{ }^{\star \star} P<0.01,{ }^{\star \star \star} P<0.001\right) . \mathrm{rm}$, recombinant mouse.

in the colons was not altered upon IL-9 blockade, although IL-17A expression was reduced in the colon. In the colon of J $\alpha 18^{-/-}$mice adoptively transferred with IL- $9^{+}$iNKT cells, IL-9 blockade enhanced STAT1 and STAT3 expression that are associated with Th1 and Th17 differentiation, respectively. Taken together, these findings suggest that IL-9-producing iNKT cells protect against DSS-induced colitis by suppressing Th1 and Th17 responses in the colon.

To address whether IL-10 contributes to attenuation of DSSinduced colitis by IL-9-producing iNKT cells, we injected WT, $\mathrm{J} \alpha 18^{-/-}$, or J $\alpha 18^{-/-}$mice administered IL- $9^{+}$iNKT cells with
anti-IL-10 mAb. Anti-IL-10 mAb aggravated DSS-induced colitis in terms of weight loss and/or survival rates in WT, Ja18 ${ }^{-/-}$, and $\mathrm{J} \alpha 18^{-/-}$mice administered IL- $9^{+}$iNKT cells (Figure 6g-k). Moreover, anti-IL-10 mAb enhanced transcriptional levels of IFN- $\gamma$ and IL-17A in the colon from WT mice during DSS-induced colitis, whereas it did not alter those of IL-9 and TGF- $\beta$ in the colon from WT and J $\alpha 18^{-/-}$mice (Figure $6 \mathbf{h}$ ). These findings suggest that IL-9-producing iNKT cells enhance IL-10 and TGF- $\beta$ production in the colon during DSS-induced colitis, which might partly contribute to the protection of DSS-induced colitis. 

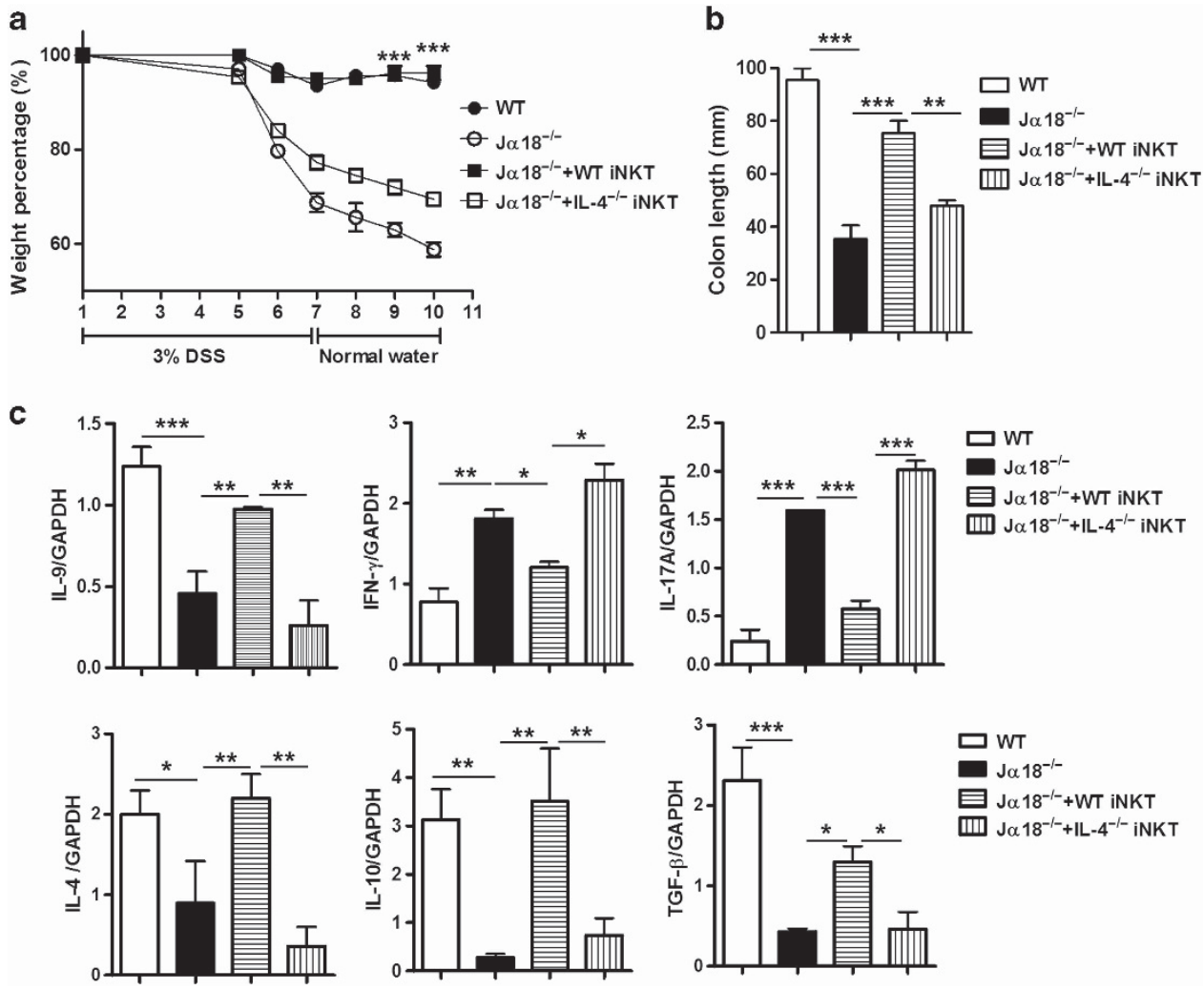

Figure 4 Adoptive transfer of wild-type (WT) cells, but not interleukin (IL)-4-deficient invariant natural killer T (iNKT) cells, attenuates dextran sulfate sodium (DSS)-induced colitis in Ja18 ${ }^{-/-}$mice. (a) Body weights (percentage of body weight relative to the initial body weight) of WT, Ja18 ${ }^{-/-}$, and J $\alpha 18^{-/-}$mice adoptively transferred with WT or IL-4-deficient iNKT cells were measured after 3\% DSS treatment. (b) Colon lengths in these mice were measured 10 days after $3 \%$ DSS treatment. (c) IL-4, IL-9, IL-10, IL-17, interferon (IFN)- $\gamma$, and tumor growth factor (TGF)- $\beta$ transcript levels in the colons from these mice were estimated 10 days after $3 \%$ DSS treatment using real-time polymerase chain reaction (PCR). Data are representative of three repeated independent experiments $\left(n=4 ;{ }^{\star} P<0.05,{ }^{\star \star} P<0.01,{ }^{\star \star \star} P<0.001\right)$. GAPDH, glyceraldehyde 3-phosphate dehydrogenase.

\section{DISCUSSION}

In our experiments, J $\alpha 18^{-/-}$mice aggravated DSS-induced colitis compared with WT B6 mice, which was restored by the adoptive transfer of WT iNKT cells, indicating that iNKT cells play a protective role in DSS-induced colitis. Consistent with our experiments, DX5 ${ }^{+} \mathrm{NKT}$ cells prevented $\mathrm{CD} 62 \mathrm{~L}^{+} \mathrm{CD} 4^{+}$ T-cell transfer-mediated colitis in severe combined immunodeficiency mice in a CD1d- and PD-L1-dependent manner, ${ }^{14}$ and the adoptive transfer of ex vivo immune-programmed NKT cells alleviated 2,4,6-trinitrobenzene sulfonic acid-induced colitis by regulating Th1/Th 2 cytokine production. ${ }^{15}$ In contrast to our experiments, NKT cells promote oxazolone-induced colitis by producing IL-13. ${ }^{10}$ Neutralization of IL-13, the depletion of NKT cells, or inhibition of NKT cell activation via anti-CD1d $\mathrm{mAb}$ attenuates oxazolone-induced colitis. ${ }^{10}$ In ulcerative colitis, IL-13 is a crucial effector cytokine that impairs intestinal epithelial cells by altering their apoptotic status and tight junctions. ${ }^{16}$ These findings suggest that the impairment of colonic epithelial cells is attributable to NKT cell-mediated cytotoxicity and IL-13 production, regulating ulceration and inflammation in patients with ulcerative colitis. ${ }^{17}$ Taken together, these findings suggest that iNKT cells play a protective or pathogenic dual role in colitis by producing IL-9 and IL-13, depending on the antigenic characterization and inflammatory progress in the colon.

Our experiments demonstrated that iNKT cells produce IL-9 upon TCR stimulation alone in vitro and in vivo, which was enhanced under IL-9-polarizing conditions. Consistent with Th9 cells, ${ }^{18,19}$ iNKT cells enhanced PU.1 and IRF4 expression under IL-9-polarizing conditions, but suppressed T-bet and GATA-3 expression. However, iNKT cells minimally expressed PU.1 and IRF4 upon TCR stimulation alone, although these cells enhanced T-bet and GATA-3 expression. These findings indicate that IL-9 production by iNKT cells is functionally associated with PU.1 and IRF4 expression rather than T-bet and GATA-3 in IL-9-polarizing conditions, whereas iNKT cells stimulated with TCR alone produce IL-9 in a PU.1- and IRF4-independent manner. These findings suggest that iNKT cells have distinct functional mechanisms for IL-9 production compared with conventional Th9 cells. However, in the DSS-induced colitis model, IL-9+ ${ }^{+}$iNKT cells increased IL-9, IL-10, PU.1, and IRF4 in J $\alpha 18^{-/-}$mice, whereas the IL-9- ${ }^{-}$iNKT cells did not affect the cytokine levels or transcription factors in the colon of J $\alpha 18^{-/-}$ mice. Moreover, serum and colonic IL-4 and TGF- $\beta$ levels were high in WT mice compared with J $\alpha 18^{-/-}$mice during DSS-induced colitis. Therefore, it is more likely that iNKT cells 
a

$\bullet-W T=J a 18^{-i-}+W T$ Th9 (LL-9+ iNKT)

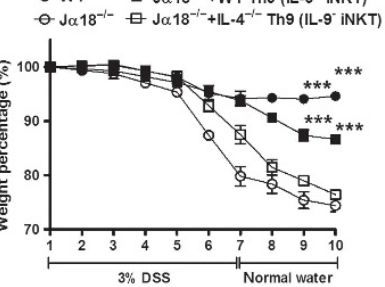

b

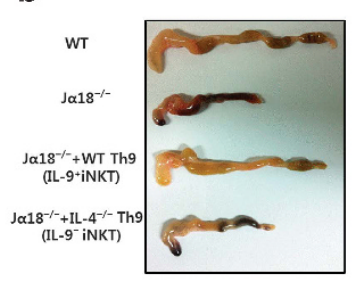

c 口T

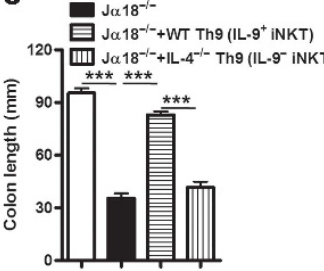

d

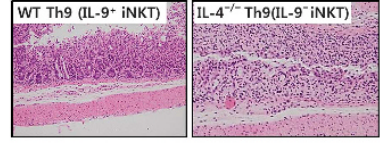

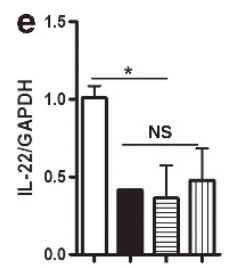
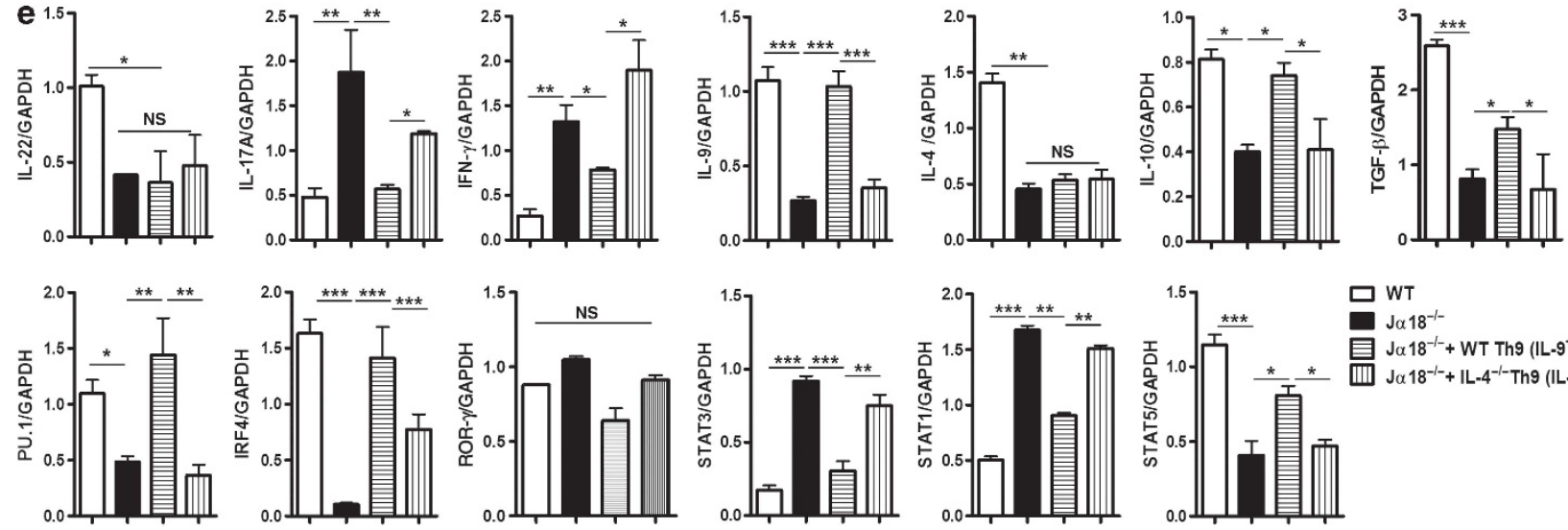

$\square$ WT

$\mathrm{J} \alpha 18^{-1-}$

目 Ja $18^{-1-}+$ WT Th9 (IL-9+ iNKT)

$\mathrm{J} \alpha 18^{-1-}+\mathrm{IL}-4^{-1-}$ Th9 (IL-9- iNKT)

Figure 5 Interleukin (IL)-9-producing invariant natural killer T (iNKT) cells attenuate dextran sulfate sodium (DSS)-induced colitis. Sorted wild-type (WT) (IL-9+ iNKT) or IL-4-deficient iNKT cells (IL-9- iNKT) were pre-incubated with anti-CD3 + CD28+interferon (IFN)- $\gamma$ monoclonal antibody (mAb), recombinant IL-4, tumor growth factor (TGF)- $\beta$, and IL-2. (a) Body weights of WT, J $\alpha 18^{-/-}$, and J $\alpha 18^{-/-}$mice adoptively transferred with IL-9 $9^{+}$or IL-9- iNKT were measured during 3\% DSS-induced colitis. (b and c) Lengths of the colons from these mice were estimated 10 days after $3 \%$ DSS treatment. (d) Histological examination of the colons of $\mathrm{J} \alpha 18^{-/-}$mice adoptively transferred with IL-9+ or IL-9- iNKT were performed 10 days after $3 \%$ DSS treatment (hematoxylin and eosin (H\&E) staining, original magnification $\times 100$ ). (e) IL-4, IL-9, IL-10, IL-17A, IL-22, IFN- $\gamma$, TGF- $\beta$, signal transducer and activator of transcription (STAT)1, STAT3, STAT5, IFN regulatory factor 4 (IRF4), ROR $\gamma$ t, and PU.1 transcript levels of the colons were determined using real-time polymerase chain reaction (PCR) 10 days after $3 \%$ DSS treatment. Data are from a representative of three repeated independent experiments $\left(n=5 ;{ }^{\star} P<0.05,{ }^{\star \star} P<0.01,{ }^{\star \star \star} P<0.001\right)$. GAPDH, glyceraldehyde 3-phosphate dehydrogenase; NS, nonsignificant.

produce IL-9 under IL-9-polarizing conditions rather than TCR stimulation alone during DSS-induced colitis. Furthermore, in vitro and in vivo data suggest that IL-4 might be crucial for the induction of IL-9-producing iNKT cells during DSS-induced colitis.

In our current experiments, IL- $9^{+}$iNKT cells attenuated DSSinduced colitis in $\mathrm{J} \alpha 18^{-/-}$mice in terms of body weight, intestinal length, and histological alterations, whereas IL-9- ${ }^{-}$iNKT cells failed to alter colitis. Moreover, anti-IL-9 mAb restored DSSinduced colitis in WT and J $\alpha 18^{-/-}$mice adoptively transferred with IL-9 ${ }^{+}$iNKT cells compared with control IgG, indicating that iNKT cells attenuate DSS-induced colitis by producing IL-9 in the colon. In contrast to our experiments, the adoptive transfer of IL- $9^{+}$IL- $10^{+}$effector T cells aggravates CD45RB ${ }^{\text {hi }}$ $\mathrm{CD} 4^{+} \mathrm{T}$-cell-induced colitis in $\mathrm{RAG1} 1^{-/-}$mice, the pathogenesis of which appears to differ from that of DSS-induced colitis. ${ }^{4}$ Although the functional role of IL-9 is still unclear in the chronic colitis models, it is conceivable that the type of IL-9-producing cells, a different colonic microenvironment, and the stage of colitis may affect the development and progression of inflammatory bowel diseases. However, it should be further explored whether IL-9-producing iNKT cells play critical role in the regulation of inflammatory bowel diseases in humans, because DSS-induced colitis is a typical model for inflammatory and repair response for acute intestinal tissue injury.

IL-22 is a crucial cytokine that plays a protective role in chronic colitis. ${ }^{20}$ In our experiments, WT mice showed higher IL-22 transcript levels in the colon than $\mathrm{J} \alpha 18^{-/-}$mice during DSS-induced colitis. However, both IL- $9^{+}$and IL- $9^{-}$iNKT cells did not alter the expression levels of IL-22. Moreover, IL-9 blockade did not affect colonic IL-22 levels in J $\alpha 18^{-/-}$mice administered IL- $9^{+}$iNKT cells, suggesting that IL- ${ }^{+}$iNKT minimally regulates colonic IL-22 production during DSSinduced colitis. On the basis of these findings, we hypothesize that iNKT cells partially contribute to the protection against DSS-induced colitis by the IL-9-independent IL-22 regulation. During DSS-induced colitis, ROR $\gamma \mathrm{t}$ expression in the colons was not altered upon IL-9 blockade, although IL-17A expression was reduced in the colon, which might be due to non-Th17 cell subset expressing ROR $\gamma \mathrm{t}$ such as lymphoid-tissue inducer cells and ROR $\gamma \mathrm{t}^{+} \mathrm{NKp} 46{ }^{+}$cells producing IL-22. ${ }^{21}$ However, IL-9 blockade enhanced STAT1 and STAT3 expression in the colon of $\mathrm{J} \alpha 18^{-1-}$ mice adoptively transferred with IL- $9^{+}$iNKT cells, supporting that IL-9-producing iNKT cells protect against DSS-induced colitis by suppressing Th1 and Th17 responses in the colon. ${ }^{1}$ However, IFN- $\gamma$ production in the colon peaked 

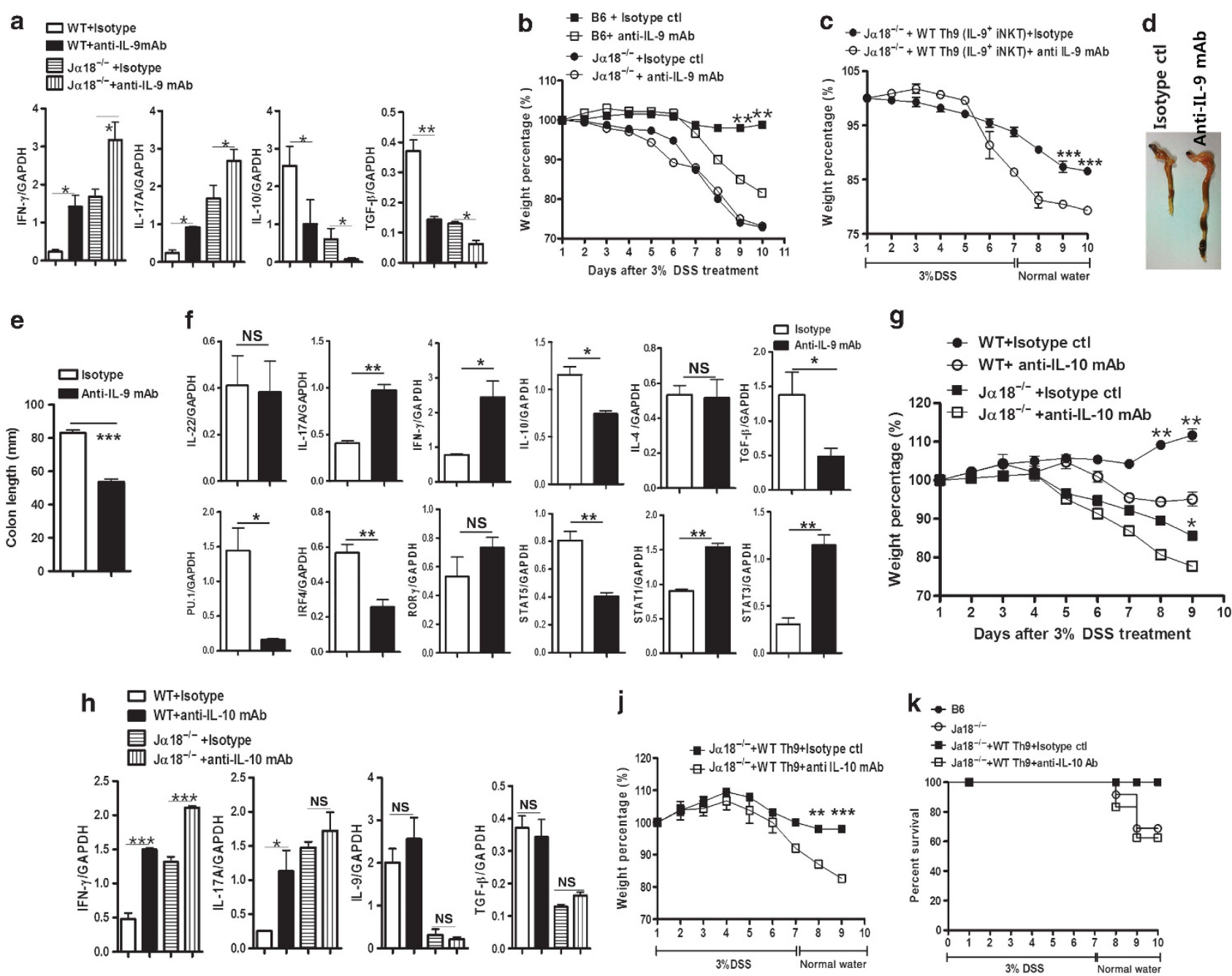

Figure 6 Interleukin (IL)-9 production by invariant natural killer T (iNKT) cells suppresses interferon (IFN)- $\gamma$ and IL-17A, thereby attenuating dextran sulfate sodium (DSS)-induced colitis. (a) Transcriptional levels of cytokines in the colon and (b) body weights of wild-type (WT), Ja18 ${ }^{-/-}$, and Ja18 ${ }^{-/-}$ mice adoptively transferred with IL- $9^{+}$or IL- $9^{-}$iNKT were estimated during $3 \%$ DSS-induced colitis. (c-e) Sorted WT iNKT cells (IL-9+ iNKT) were pre-incubated with anti-CD3 + CD28 + interferon (IFN)- $\gamma$ monoclonal antibody (mAb), recombinant IL-4, tumor growth factor (TGF)- $\beta$, and IL-2. Anti-IL-9 mAb or control (ctl) immunoglobulin $\mathrm{G}(\mathrm{IgG})$ was intravenously injected into $\mathrm{J} \alpha 18^{-/-}$mice administered IL- $9^{+}$iNKT cells. (c) The body weights of these mice were estimated during $3 \%$ DSS-induced colitis. (d and e) Colon lengths from these mice were measured 10 days after $3 \%$ DSS treatment. (d) IL-4, IL-10, IL-17A, IL-22, IFN- $\gamma$, TGF- $\beta$, IFN regulatory factor 4 (IRF4), PU.1, signal transducer and activator of transcription (STAT)1, STAT3, STAT5, and ROR $\gamma$ t transcript levels were estimated in the colons from these mice 10 days after $3 \%$ DSS treatment. (g and $\mathbf{h}$ ) Anti-IL-10 mAb or control lgG was intravenously injected into WT and $\mathrm{J} \alpha 18^{-/-}$mice during DSS-induced colitis. (g) The body weights and (h) cytokine levels in the colons of these mice were measured. ( $\mathbf{j}$ and $\mathbf{k}$ ) Anti-IL-10 mAb or control IgG was intravenously injected into Ja18 ${ }^{-/-}$mice administered IL-9+ iNKT cells and (j) the body weights and $(\mathbf{k})$ survival rates of these mice were measured. Data are representative of three repeated independent experiments $\left(n=5 ;{ }^{*} P<0.05\right.$, $\left.{ }^{\star \star} P<0.01,{ }^{* \star} P<0.001\right)$. GAPDH, glyceraldehyde 3-phosphate dehydrogenase; NS, nonsignificant.

on earlier time point during DSS-induced colitis than did IL-9 production. On the basis of these findings, it is less likely that IL-9-producing iNKT cells regulate IFN- $\gamma$ production during DSS-induced colitis. Nevertheless, blockade of IL-9 using $\mathrm{mAb}$ significantly enhanced transcriptional levels of IFN- $\gamma$ and IL-17A in the colon from WT and J $\alpha 18^{-/-}$mice adoptively transferred with IL-9+ ${ }^{+}$iNKT cells with colitis. Therefore, these findings indicate that IL-9-producing iNKT cells suppress IFN$\gamma$ and IL-17 production in the colon during colitis, although IFN- $\gamma$ production appears earlier than IL-9 production. This phenomenon should be further explored. Consistent with our results, Ueno et al. ${ }^{22}$ demonstrated that a single dose of $\mathrm{OCH}$ attenuated DSS-induced colitis in WT mice, but not J $\alpha 18^{-1-}$ mice, suggesting that iNKT cells protect against DSS-induced colitis by altering the mucosal Th1/Th2 response. Moreover, recent study has demonstrated that dysregulation of type II NKT cells in CD1dTg/24 $\alpha \beta \mathrm{Tg}$ mice leads to spontaneous colitis. ${ }^{23}$ Upon anti-CD3 stimulation, a higher proportion of type II NKT cells in the colon of these mice produced IFN- $\gamma$ and IL-17A compared with control mice, which might partially account for the development of spontaneous colitis. On the basis of the counteractive interaction between type I and II NKT cells 
in several animal models, ${ }^{24,25}$ it is also conceivable that type II NKT cells contribute to intestinal inflammation by counteracting IL-9-producing iNKT cells. However, the functional roles of IL-17 in chronic colitis are controversial. Yang et al. ${ }^{26}$ demonstrated that IL-17 ${ }^{-/}$mice develop more severe DSSinduced colitis, whereas IL-17F-deficient mice show reduced colitis, suggesting that IL-17F rather than IL-17A contributes to promoting DSS-induced colitis. However, Th17 cells possess considerable plasticity and acquire the ability to produce IFN- $\gamma$ in addition to IL-17A production or completely fail to produce IL-17 in vitro and in vivo. ${ }^{27,28}$ Furthermore, portion of T cells produce both IFN- $\gamma$ and IL-17 in the gut of patients with Crohn's disease. ${ }^{27}$ These findings suggest that the IL-9producing iNKT cell-mediated suppression of IL-17A may contribute to protecting DSS-induced colitis by shutting off the Th1 response, although IL-17A may partially attenuate colitis. Meanwhile, anti-IL-9 mAb reduced transcriptional levels of IL10 and TGF- $\beta$ in the colon from WT, J $\alpha 18^{-/-}$, and J $\alpha 18^{-/-}$ mice adoptively transferred with IL- $9^{+}$iNKT cells. Moreover, anti-IL-10 mAb aggravated DSS-induced colitis in these mice, suggesting that IL-10 contributes to attenuating DSS-induced colitis in IL- ${ }^{+}$iNKT cell-dependent and iNKT cell-independent manners. However, anti-IL-10 mAb did not alter TGF- $\beta$ production in the colon from WT and J $\alpha 18^{-/-}$mice during DSS-induced colitis. These findings suggest that IL-9-producing iNKT cells enhance IL- 10 and TGF- $\beta$ production in the colon during DSS-induced colitis.

In conclusion, IL-9-producing iNKT cells protect against DSS-induced colitis by suppressing IFN- $\gamma$ and IL-17A production, but enhancing IL- 10 and TGF- $\beta$ production in the colon. Furthermore, iNKT cells produce IL-9 in the presence of TCR stimulation in an IL-4-dependent manner, which is enhanced by IL-9-polarizing conditions.

\section{METHODS}

Mice. C57BL/6 (B6) mice were purchased from the Orient Company (Seoul, Korea). CD1d $\mathrm{d}^{-/-}$and $\mathrm{J} \alpha 18^{-/-}$mice were obtained from the NIAID-Taconic facility of the National Institutes of Health (Dr Hua Gu, Columbia University, New York, NY), and Dr M. Taniguchi (Chiba University, Chiba, Japan), respectively. IL-4 ${ }^{-/-}$and IFN $-\gamma^{-/-}$mice were purchased from The Jackson Laboratory (Bar Harbor, ME). These mice were bred and maintained under specific pathogen-free conditions at the Clinical Research Institute Seoul National University Hospital. All animal experiments were approved from the Institutional Animal Care and Use Committee at the Seoul National University Hospital.

In vitro cell culture and reagents. Recombinant mouse (rm) IL-4 (20 $\mathrm{ng} \mathrm{ml}^{-1}$ ) was purchased from eBioscience (San Diego, CA). Purified rat anti-mouse CD124 (IL-4R; $20 \mathrm{ng} \mathrm{ml}^{-1}$ ) was purchased from BD Bioscience (San Diego, CA). Anti-mouse IFN- $\gamma \mathrm{R}\left(1 \mu \mathrm{g} \mathrm{ml}^{-1}\right)$ and rmIFN- $\gamma\left(10 \mathrm{ng} \mathrm{ml}^{-1}\right)$ were purchased from R\&D Systems (Minneapolis, MN). LMNCs of B6 or IL-4 $4^{-1-}$ mice were cultured with or without $200 \mathrm{ng} \mathrm{ml}^{-1}$ of $\alpha$-GalCer and rmIL- 4 or anti-mouse CD124 $\mathrm{mAb}$. In the case of IFN- $\gamma^{-1-}$ mice, cells were cultured with or without $\alpha$-GalCer $\left(200 \mathrm{ng} \mathrm{ml}^{-1}\right)$ and rmIFN- $\gamma$ or anti-IFN- $\gamma$ receptor $\mathrm{mAb}$ for 3 days.

Immune cell preparation from the colon. To prepare colonic immune cells, the colon was cut longitudinally in the Petri dish and washed with phosphate-buffered saline (PBS) after removing colonic contents.
The colon was cut into $0.5 \mathrm{~cm}$ small pieces, which were incubated with $1 \mathrm{M}$ dithiothreitol (Biosesang, Seongnam, Korea) at $37^{\circ} \mathrm{C}$ for $15 \mathrm{~min}$. After incubation, colonic pieces were filtered in $40 \mu \mathrm{m}$ strainer, and then centrifuged at $300 \mathrm{~g}$ for $7 \mathrm{~min}$. Cell pellet $(5 \mathrm{ml})$ was transferred onto percoll-gradient (40 vs. $20 \%$ ) solution (Amersham Pharmacia Biotech AB, Uppsala, Sweden) carefully, which was centrifuged at 2,000 r.p.m. for $15 \mathrm{~min}$ without break. Colonic immune cells were taken from interface between 20 and $40 \%$ percoll solution.

In vitro induction of IL-9-producing iNKT cells. Naïve CD4 ${ }^{+} \mathrm{T}$ cells were purified from the spleen of mice using MACS microbeads (Miltenyi Biotec, Auburn, CA). $\alpha$-GalCer/CD1d tetramer ${ }^{+}$iNKT cells were sorted from the LMNCs using FACS Aria II (Becton Dickinson, San Jose, CA). The tetramer facility at the National Institutes of Health (Bethesda, MD) provided CD1d tetramers loaded with PBS-57. The purity of sorted populations was $>98 \%$. To polarize NKT cells toward a IL-9-producing lineage, LMNC cells or sorted iNKT cells were cultured with plate-bound anti-mouse CD3 $\left(5 \mu \mathrm{g} \mathrm{ml}^{-1}\right)+\mathrm{CD} 28 \mathrm{mAb}\left(5 \mu \mathrm{g} \mathrm{ml}^{-1}\right)$, rmIL-4 $\left(10 \mathrm{ng} \mathrm{ml}^{-1}\right)$, rmTGF- $\beta$ $\left(20 \mathrm{ng} \mathrm{ml}^{-1}\right)$, rmIL-2 $\left(20 \mathrm{ng} \mathrm{ml}^{-1}\right)$, and anti-mouse IFN- $\gamma \mathrm{mAb}$ $\left(10 \mu \mathrm{g} \mathrm{ml}^{-1}\right)$ for 3 days, referred to as IL-9-polarizing conditions. These antibodies were obtained from BD Bioscience and all recombinant cytokines were obtained from eBioscience. After 3 days, cells were stimulated with $1 \mu \mathrm{g} \mathrm{ml}^{-1}$ concanavalin A (Sigma Chemical, St Louis, MO) for $6 \mathrm{~h}$ for intracellular staining. Cells were cultured in RPMI 1640 medium and supplemented with $10 \%$ fetal bovine serum (Hyclone, Logan, UT) and 1\% penicillin streptomycin (GIBCO BRL, Eggenstein, Germany).

Real-time polymerase chain reaction analysis. To perform real-time polymerase chain reaction (PCR), total RNA was isolated from whole colons using an RNeasy kit (Qiagen, Courtaboeuf, France) according to the manufacturer's instructions. RNA was reverse transcribed into cDNA using a MMLV-RT Taq polymerase (Promega, Madison, WI) before PCR. For quantitative real-time PCR, gene-specific PCR products were measured using an Applied Biosystems 7500 Sequence Detection System (Perkin-Elmer Biosystem, Foster City, CA), and the results for each cytokine were normalized to glyceraldehyde 3-phosphate dehydrogenase (GAPDH) expression. The following primers and probe were synthesized by Applied Biosystems: GAPDH (4352339E), IFN- $\gamma$ (Mm 00801778 m1), IL-4 (Mm 00445259_m1), IL-9 (Mm 00434305_m1), IL-10 (Mm 00439614_m1), T-bet (Mm01299452_g1), GATA-3 (Mm00484683 m1), and PU.1 (Mm 00488428_m1); IRF4 (Mm 00516431_m1), STAT1 (Mm 00439531_m1), STAT3 (Mm 01219775_m1), STAT5 (Mm 00839861_m1), IL-22 (Mm 00444241_m1), ROR $\gamma \mathrm{t}$ (Mm 01261022_m1), and TGF- $\beta_{1}\left(5^{\prime}\right.$-GCAACATGTGGAACTCTACCAGAA-3' for forward, 5'-GACGTCAAAAGACAGCCACTCA-3' for reverse, and FAM5'-ACCTTGGTAACCGGCTGCTGACCC-3' -TAMRA).

Enzyme-linked immunosorbent assay. To measure the cytokine levels, sera and cell culture supernatants were collected. All cytokine enzyme-linked immunosorbent assay (ELISA) kits were obtained from BD Biosciences, except IL-17, and used according to the manufacturer's instructions. The reaction was stopped with $3 \mathrm{~N}$ hydrochloric acid, and the absorbance was measured at 450 and $570 \mathrm{~nm}$.

DSS-induced colitis and histological examination. WT and J $\alpha 18^{-/-}$ mice were administered 3\% (wt vol ${ }^{-1}$ ) DSS (Wako, Osaka, Japan) in drinking water for 7 days. The body weights were monitored daily. Colon length was measured with a caliper (Manostat, Geneva, Switzerland) 10 days after drinking DSS-containing water. To estimate survival, mice were administered drinking water containing 3.5\% ( $\mathrm{wt} \mathrm{vol}^{-1}$ ) DSS. To examine histological changes in the colon, whole colons were fixed in $4 \%$ formalin and embedded in paraffin. Sections were prepared from the colon blocks and stained with hematoxylin and eosin. 
Intracellular cytokine staining. For intracellular IL-9 staining, cells were incubated with GolgiPlug (BD Pharmingen, San Diego, CA) for 4-6h. Cells were surface stained with fluorescein isothiocyanate-conjugated anti-mouse $\mathrm{CD} 3 \mathrm{mAb}$ (BD Pharmingen) and allophycocyaninconjugated $\alpha$-GalCer/CD1d tetramer or allophycocyanin-conjugated Lineage antibody cocktail and phycoerythrin-cy7-conjugated anti-Thy $1.2 \mathrm{mAb}$ (BD Pharmingen). Thereafter, these cells were incubated with $200 \mu \mathrm{l}$ fixation/permeabilization solution of Cytofix/Cytoperm (BD Pharmingen) for $20 \mathrm{~min}$. After washing with $1 \mathrm{ml}$ of BD $1 \times$ Perm/Wash buffer, the cells were stained with phycoerythrin-conjugated anti-mouse IL-9 mAb (D9302C12; BD Pharmingen) overnight at $4^{\circ} \mathrm{C}$.

Adoptive transfer experiments and IL-9 or IL-10 neutralization in vivo. Sorted iNKT cells $\left(2 \times 10^{5}\right)$ or pre-cultured iNKT $\left(5 \times 10^{5}\right)$ cells of B6 or IL- $4^{-/-}$mice under IL-9-polarizing conditions were adoptively transferred into J $\alpha 18^{-1-}$ mice via intravenous injection 1 day before DSS treatment. To neutralize IL-9 in vivo, anti-mouse IL-9 mAb (100 $\mu$ g per mouse; $\mathrm{R} \& \mathrm{D}$ Systems) or isotype control $\mathrm{mAb}$ (goat IgG; R\&D Systems) were injected 5, 7, and 9 days after DSS treatment via intraperitoneal injection. To neutralized IL-10 in vivo, anti-mouse IL-10 mAb (100 $\mu$ g per mouse; eBioscience) or isotype-matched control mAb (rat IgG1, $\kappa$; eBioscience) were intravenously injected 2, 4, 6, and 8 days after DSS treatment.

Statistical analyses. Statistical significance was analyzed using Prism ver. 5.0 (GraphPad Software, San Diego, CA). A $t$-test was performed to compare the two groups. To compare multiple groups, a one-way analysis of variance using Tukey's post hoc test was used. A $P<0.05$ was considered statistically significant.

\section{ACKNOWLEDGMENTS}

We thank all members of the Department of Experimental Animals at the Clinical Research Institute of Seoul National University Hospital for animal management. We also thank NIAID Tetramer Facility at the National Institutes of Health, USA, for providing PBS-57-loaded CD1d tetramers. This work was supported by a National Research Foundation of Korea (NRF) grant funded by the Korean government (2012-0005652).

\section{DISCLOSURE}

The authors declared no conflict of interest.

(c) 2013 Society for Mucosal Immunology

\section{REFERENCES}

1. Palmer, M.T. \& Weaver, C.T. Autoimmunity: increasing suspects in the CD4+ T cell lineup. Nat. Immunol. 11, 36-40 (2010).

2. O'Shea, J.J.\& Paul, W.E. Mechanisms underlying lineage commitment and plasticity of helper CD4+ T cells. Science 327, 1098-1102 (2010).

3. Veldhoen, M. et al. Transforming growth factor-beta 'reprograms' the differentiation of Thelper 2 cells and promotes an interleukin 9-producing subset. Nat. Immunol. 9, 1341-1346 (2008).

4. Dardalhon, V. et al. IL-4 inhibits TGF-beta-induced Foxp3+ T cells and, together with TGF-beta, generates IL-9+ IL-10+ Foxp3(-) effector T cells. Nat. Immunol. 9, 1347-1355 (2008).

5. Goswami, R. \& Kaplan, M.H. A brief history of IL-9. J. Immunol. 186, 3283-3288 (2011).

6. Bendelac, A. CD1: presenting unusual antigens to unusual T lymphocytes. Science 269, 185-186 (1995).

7. Gumperz, J.E., Miyake, S., Yamamura, T. \& Brenner, M.B. Functionally distinct subsets of CD1d-restricted natural killer T cells revealed by CD1d tetramer staining. J. Exp. Med. 195, 625-636 (2002).
8. Sonoda, K.H., Faunce, D.E., Taniguchi, M., Exley, M., Balk, S. \& Stein-Streilein, J. NK T cell-derived IL-10 is essential for the differentiation of antigen-specific T regulatory cells in systemic tolerance. J. Immunol. 166, 42-50 (2001).

9. Akbari, O. et al. Essential role of NKT cells producing IL-4 and IL-13 in the development of allergen-induced airway hyperreactivity. Nat. Med. 9, 582-588 (2003).

10. Heller, F., Fuss, I.J., Nieuwenhuis, E.E., Blumberg, R.S. \& Strober, W. Oxazolone colitis, a Th2 colitis model resembling ulcerative colitis, is mediated by IL-13-producing NK-T cells. Immunity 17, 629-638 (2002).

11. Yoshimoto, T. et al. Nonredundant roles for CD1d-restricted natural killer T cells and conventional CD4+ T cells in the induction of immunoglobulin $\mathrm{E}$ antibodies in response to interleukin 18 treatment of mice. J. Exp. Med. 197, 997-1005 (2003).

12. Coquet, J.M. et al. Diverse cytokine production by NKT cell subsets and identification of an IL-17-producing CD4 - NK1.1 - NKT cell population. Proc. Natl. Acad. Sci. USA 105, 11287-11292 (2008).

13. Lauwerys, B.R., Garot, N., Renauld, J.C. \& Houssiau, F.A. Cytokine production and killer activity of NK/T-NK cells derived with IL-2, IL-15, or the combination of IL-12 and IL-18. J. Immunol. 165, 1847-1853 (2000).

14. Hornung, M., Farkas, S.A., Sattler, C., Schlitt, H.J. \& Geissler, E.K. DX5+ NKT cells induce the death of colitis-associated cells: involvement of programmed death ligand-1. Eur. J. Immunol. 36, 1210-1221 (2006).

15. Shibolet, O. et al. Adoptive transfer of ex vivo immune-programmed NKT lymphocytes alleviates immune-mediated colitis. J. Leukocyte Biol. 75, 76-86 (2004).

16. Heller, F. et al. Interleukin-13 is the key effector Th2 cytokine in ulcerative colitis that affects epithelial tight junctions, apoptosis, and cell restitution. Gastroenterology 129, 550-564 (2005).

17. Strober, W. \& Fuss, I.J. Proinflammatory cytokines in the pathogenesis of inflammatory bowel diseases. Gastroenterology 140, 1756-1767 (2011).

18. Staudt, V. et al. Interferon-regulatory factor 4 is essential for the developmental program of T helper 9 cells. Immunity 33, 192-202 (2010).

19. Chang, H.C. et al. The transcription factor PU.1 is required for the development of IL-9-producing T cells and allergic inflammation. Nat. Immunol. 11, 527-534 (2010).

20. Sugimoto, K. et al. IL-22 ameliorates intestinal inflammation in a mouse model of ulcerative colitis. J. Clin. Invest. 118, 534-544 (2008).

21. Vivier, E., Spits, H. \& Cupedo, T. Interleukin-22-producing innate immune cells: new players in mucosal immunity and tissue repair? Nat. Rev. Immunol. 9, 229-234 (2009).

22. Ueno, Y. et al. Single dose of OCH improves mucosal Thelper type $1 / \mathrm{T}$ helper type 2 cytokine balance and prevents experimental colitis in the presence of valpha14 natural killer T cells in mice. Inflamm. Bowel Dis. 11, 35-41 (2005).

23. Liao, C.M., Zimmer, M.I., Shanmuganad, S., Yu, H.T., Cardell, S.L. \& Wang, C.R. Dysregulation of CD1d-restricted type II natural killer T cells leads to spontaneous development of colitis in mice. Gastroenterology 142, 326-334 (2011).

24. Terabe, M. et al. A nonclassical non-Valpha14Jalpha18 CD1d-restricted (type II) NKT cell is sufficient for down-regulation of tumor immunosurveillance. J. Exp. Med. 202, 1627-1633 (2005).

25. Zhang, G. et al. Sulfatide-activated type II NKT cells prevent allergic airway inflammation by inhibiting type I NKT cell function in a mouse model of asthma. Am. J. Physiol. Lung Cell Mol. Physiol. 301, 975-984 (2011).

26. Yang, X.O. et al. Regulation of inflammatory responses by IL-17F. J. Exp. Med. 205, 1063-1075 (2008).

27. Annunziato, F. et al. Phenotypic and functional features of human Th17 cells. J. Exp. Med. 204, 1849-1861 (2007).

28. Hirota, K. et al. Fate mapping of IL-17-producing T cells in inflammatory responses. Nat. Immunol. 12, 255-263 (2011). 